per move). Why? The first move they considered was disproportionately likely to be a good one. Klein argues that the more experience a decision-maker has in a domain, the better he or she is at satisficing in that domain. So the training programmes designed by Klein's company tend to involve teaching novices how to satisfice like experts rather than using rational decision-making methods.

Klein tries to account for expert decisionmaking with the 'recognition-primed decision' (RPD) model. Its first stage amounts to categorization of the situation. As well as a default course of action, this categorization activates 'expectancies' that help the decision-maker to detect anomalies. If there is a glitch, he or she can turn to mental simulation or analogical reasoning to tailor a new course of action.

Unfortunately, because Klein does not explain in detail how he and his colleagues analysed the interviews that serve as their primary data source, some of the quantitative findings reported in the book are difficult to interpret. Moreover, his efforts to ground the RPD model in basic research in psychology are spotty and idiosyncratic, which might irk some knowledgeable readers. The RPD model does not elucidate anything about naturalistic decision-making that cannot be gleaned from the book's numerous (and occasionally fascinating) case studies.

Why is satisficing not generally advocated by decision theorists? Part of the answer is that decisions based on this method are difficult to justify after the fact. Although many organizations train their people to use transparent, rational procedures, experienced decision-makers tend not to apply them. Decisions that look wrong in retrospect are often blamed on deviations from rational methods.

In July 1988, for example, during the Iran-Iraq war, the crew of the USS Vincennes shot down what turned out to be a commercial aircraft in the Persian Gulf in the belief that it was an Iranian fighter plane. One decision analyst later argued that expectancy bias distorted the commander and crew's interpretation of the information about the plane's speed and altitude. However, as Klein observes, if the plane had turned out to be a fighter, the same analyst could have blamed the error on base-rate neglect: in the previous month, most of the aircraft identified by the US forces in the Middle East had been Iranian military planes.

In hindsight, the decision to shoot was clearly an error, but, as reconstructed by Klein, it seems to have been reasonable given the information available.

Klein has amassed an impressive quantity and range of evidence that erodes the myth of the expert decision-maker who behaves according to classical rational models, and he suggests that traditional definitions of both rationality and expertise need to be re-examined.

Valerie M. Chase is at the Center for Adaptive Behavior and Cognition, Max Planck Institute for Human Development, Lantzeallee 94, 14195 Berlin, Germany.

\section{Benevolent nuclei}

\section{Tracks to Innovation}

by Robert L. Fleischer

Springer: 1998. Pp. 193. \$49.95, £37.50

\section{Robert W. Cahn}

The best book titles leave the potential reader intrigued and prone to curiosity. The title of Robert L. Fleischer's book is loaded with meaning. The overt subject matter is the tracks left in insulating materials by highenergy subatomic projectiles. Improbable though it might seem, the study of such tracks has led to a range of profitable industrial innovations (as well as to scientific insights of inestimable value).

Fleischer spent many years as a research physicist at the Corporate Research Center of General Electric in upper New York State. There his colleagues Buford Price and Robert Walker discovered, in 1961, that fission fragments from uranium leave behind damage traces, known as 'tracks', in slivers of mica, and that these tracks can be revealed by a chemical etchant, which penetrates along the tracks much faster than it eats away the bulk of the mica. As Fleischer points out, this serendipitous observation owed something to the fact that a colleague had squirrelled away a supply of high-quality synthetic mica made as a reserve in time of war, and another pair of investigators there had recently found out how to reveal dislocation lines in lithium fluoride by etching.

The following year, Price and Walker teamed up with Fleischer to pursue this discovery. Someone in the laboratory needed a controlled, ultraslow vacuum leak, and it occurred to the trio that etching the tracks right through a piece of mica could provide this, and indeed it did. The diameter of the hole increased with longer etching time, and the relationship was highly reproducible.

From that point on (and later with the help of an experienced nuclear physicist, Antonio Mogro-Campero), the trio combined fundamental studies with searches for applications. They examined such issues as the relative 'etchability' of tracks in different materials, crystalline or amorphous, the threshold dose to render a track etchable at all, the relative effectiveness of alpha particles and fission fragments of different energies (beta and gamma rays are ineffective), and the nature of 'track holes' under different irradiation and etching conditions. After three years of this, a confidential conference was organized at General Electric involving 44 of the company's scientists and engineers from around the United States to explore the discovery's possible uses.

At about the same time, the first — highly profitable - application emerged through a chance meeting with a New York cancer researcher, who needed an ultrafilter to separate cancer cells and blood cells. It turned out that the company's own amorphous polycarbonate film was ideal for making a population of small, generally non-overlapping, perfectly round holes, from nanometres to several micrometres across, for use as ultrafilters. This process was soon commercialized by General Electric as 'Nuclepore', with an eventual annual profit of more than $\$ 10$ million. Now that the patent has expired and several companies have joined the fray, the worldwide demand for such filters for biomedical research, aerosol studies and various forms of analytical and laboratory use is about half a million square metres per year, with a value of $\$ 50$ million.

The team at General Electric perfected a bewildering array of scientific and technological uses including dosimetry of radon in houses, estimation of the time since rocks were last heated in mountain-building, and determination of plutonium distribution in an organism by a form of track-based autoradiography. The most profitable use of track technology (though the profit did not accrue to General Electric) was the use of rock-heating methodology by petroleum exploration companies: recent heating of a reservoir denatures the oil, and where such heating is deduced from a study of surface rocks, petroleum companies can save tens of millions of dollars that would otherwise have been used to drill an ineffective well.

The last chapter analyses concisely but profoundly, in the light of the 30-year adventure of track research, the uses of in-house scientific research in industry (which has steadily declined at General Electric, as it has in many companies worldwide). Fleischer points out that two observations of track etching were made at Harwell Laboratory in England before the first observations at General Electric, but led nowhere because, at the time, Harwell was not commercially orientated; General Electric was, and reaped the commercial benefit.

The important point is this: "A wealth of new opportunities can arise when people with different knowledge and interests come together." The diversity at General Electric ensured that the "boundaries of separate areas of knowledge" came together to take advantage of the work on track etching. The book provides a concise, informative, witty and easy-to-read account of this episode that is replete with lessons.

Robert W. Cahn is in the Department of Materials Science and Metallurgy, University of Cambridge, Pembroke Street, Cambridge CB2 3QZ, UK. 